\title{
Questões de gênero na consulta pré-natal de enfermagem: percepções das
}

\section{enfermeiras residentes}

Gender issues in the antenatal nursing consultation: perceptions of resident nurses

Cuestiones de género en la consulta prenatal de enfermería: percepciones de las enfermeras residentes

\section{Caroline Macedo do NascimentoI, Dayane da Silva Palha Barbosa ${ }^{\mathrm{II}}$, Adriana Lenho de Figueiredo Pereira ${ }^{\mathrm{III}}$, Ricardo José Oliveira Mouta ${ }^{\mathrm{IV}}$, Sandra Cristina de Souza Borges Silvav}

\begin{abstract}
Resumo: Objetivo: descrever as percepções das enfermeiras residentes em processo de qualificação para a assistência pré-natal acerca das questões de gênero na consulta de enfermagem. Método: estudo qualitativo, realizado com doze enfermeiras em qualificação, na modalidade de residência, nos serviços de atenção pré-natal, no município do Rio de Janeiro. As entrevistas semiestruturadas ocorreram de outubro a novembro de 2016. Aplicouse a análise de conteúdo temática. Resultados: as normas de gênero relacionam-se com valores e comportamentos tradicionais associados à maternidade e paternidade. As iniquidades advindas dessas normas são vistas como a causa da violência às mulheres e do limitado envolvimento masculino na gestação. Há restrições de uma perspectiva de gênero nos serviços, apesar de haver homens que buscam uma paternidade mais ativa e casais homoafetivos que recorrem ao atendimento pré-natal. Conclusão: propostas de intervenção com enfoque nessa perspectiva são necessárias na assistência pré-natal e qualificação profissional, em âmbito individual e coletivo.

Descritores: Gênero e saúde; Enfermagem; Cuidado pré-natal; Minorias sexuais e de gênero; Saúde reprodutiva
\end{abstract}

Abstract: Objective: to describe the perceptions of resident nurses in the process of qualifying for antenatal care about gender issues in the nursing consultation. Method: qualitative study, carried out with twelve nurses in qualification, in the modality of residency, in antenatal care services, in the city of Rio de Janeiro. The semistructured interviews took place from October to November 2016. Thematic content analysis was applied. Results: gender norms are related to traditional values and behaviors associated with maternity and paternity. The

\footnotetext{
${ }^{\text {I }}$ Enfermeira. Universidade do Estado do Rio de Janeiro (UERJ). Rio de Janeiro, Rio de Janeiro, Brasil. E-mail: carolzinhaah94@gmail.com ORCID: https://orcid.org/0000-0003-4653-9741

${ }^{\text {II }}$ Enfermeira. Universidade do Estado do Rio de Janeiro (UERJ). Rio de Janeiro, Rio de Janeiro, Brasil. E-mail: dayanespb@gmail.com ORCID: https://orcid.org/0000-0002-7198-6618

III Enfermeira. Doutora em Enfermagem. Professora Associada da Faculdade de Enfermagem da Universidade do Estado do Rio de Janeiro (UERJ). Rio de Janeiro, Rio de Janeiro, Brasil. E-mail: adriana.lenho@uerj.br ORCID: https://orcid.org/0000-0002-2563-6174

IV Enfermeiro. Doutor em Enfermagem. Professor Ajunto da Faculdade de Enfermagem da Universidade do Estado do Rio de Janeiro (UERJ). Rio de Janeiro, Rio de Janeiro, Brasil. E-mail: ricardomouta@hotmail.com ORCID: https:/orcid.org/0000-0002-1284-971X

${ }^{\mathrm{v}}$ Enfermeira. Mestre em Enfermagem. Professora Assistente da Faculdade de Enfermagem da Universidade do Estado do Rio de Janeiro (UERJ). Rio de Janeiro, Rio de Janeiro, Brasil. E-mail: scrisborges@hotmail.com ORCID: https://orcid.org/0000-0001-9147-5949
} 
inequities arising from these norms are seen as the cause of violence against women and limited male involvement in pregnancy. There are restrictions from a gender perspective on services, although there are men who seek more active parenting and same-sex couples who resort to antenatal care. Conclusion: intervention proposals focusing on this perspective are necessary in antenatal care and professional qualification, individually and collectively.

Descriptors: Gender and health; Nursing; Antenatal care; Sexual and gender minorities; Reproductive health

Resumen: Objetivo: describir las percepciones de enfermeras residentes en proceso de calificación para atención prenatal sobre temas de género en la consulta de enfermería. Método: estudio cualitativo, realizado con doce enfermeras en calificación, modalidad de residencia, en servicios de atención prenatal, en la ciudad de Rio de Janeiro. Las entrevistas semiestructuradas ocurrieron de octubre a noviembre de 2016. Se aplicó el análisis de contenido temático. Resultados: normas de género están relacionadas con valores y comportamientos tradicionales asociados a maternidad y paternidad. Las desigualdades de estas normas son la causa de la violencia contra la mujer y de la limitada participación masculina en el embarazo. Hay restricciones desde una perspectiva de género en los servicios, aunque algunos hombres busquen una paternidad más activa y parejas homoafectivas recurran a la atención prenatal. Conclusión: propuestas de intervención centradas en esta perspectiva son necesarias en la atención prenatal y calificación profesional, individual y colectiva.

Descriptores: Género y salud; Enfermería; Atención prenatal; Minorías sexuales y de género; Salud reproductiva

\section{Introdução}

A assistência pré-natal visa promover a saúde e prevenir a morbimortalidade materna e neonatal. Espera-se que os profissionais de saúde exerçam cuidados qualificados e orientem as mulheres e os seus parceiros sobre os aspectos sociais, culturais, emocionais e psicológicos que envolvem a gravidez, parto e nascimento. ${ }^{1}$

Em relação às gestantes classificadas como de risco habitual e sem morbidades associadas, há predomínio dessa assistência em serviços públicos da Atenção Primária à Saúde (APS) no Brasil, como ocorre nas Unidades da Atenção Básica e da Saúde da Família, tendo a enfermagem participação relevante nesse nível de atenção. Dentre outras atribuições, as enfermeiras realizam consultas de enfermagem de modo privativo e promovem atividades educativas, juntamente com os demais profissionais de saúde..$^{1-2}$

Portanto, espera-se que a formação em enfermagem desenvolva nesses profissionais as competências e habilidades adequadas para que exerçam a profissão de forma crítica e reflexiva, 
com compreensão dos determinantes sociais da saúde, em prol da integralidade, equidade, humanização e qualidade da assistência à saúde da população. ${ }^{2}$ Contudo, apesar da ampla cobertura da atenção pré-natal, ainda são observadas iniquidades sociais que impactam nos resultados da assistência, como aquelas associadas à classe, ao gênero e à raça ou etnia. ${ }^{1-2}$ Por exemplo, mulheres com cor da pele preta ou parda e com menor nível socioeconômico apresentam taxas de adequação do pré-natal menores em comparação com as demais gestantes, o que aumenta o risco de desfechos negativos da gravidez para essas mulheres. ${ }^{3}$

Quanto ao gênero, os papéis sociais tradicionais atribuídos às mulheres e aos homens ainda tendem a ser reforçados na assistência à saúde, em que as mulheres são vistas com menos autoridade que os homens, são mais desvalorizadas e passíveis de desrespeito, abusos verbais e procedimentos coercivos ou não consentidos. No entanto, existe o direito humano fundamental da igualdade de gênero, que deve ser respeitado para que se alcance uma sociedade democrática e mais igualitária. ${ }^{4}$

Em face da magnitude das iniquidades sociais no mundo, as Nações Unidas estabeleceram os Objetivos de Desenvolvimento Sustentável (ODS) a fim de reduzir a pobreza, promover a prosperidade e o bem-estar de todas as pessoas e proteger o meio ambiente. Para isso, constituiu uma agenda de metas a ser alcançada até 2030 por seus países membros, inclusive o Brasil. O quinto ODS visa alcançar a igualdade de gênero e o empoderamento das mulheres e meninas, no intuito de reduzir as desigualdades sociais às quais metade da população mundial está exposta pelo simples fato de ser mulher. ${ }^{4-5}$

Cabe destacar que o gênero se refere a papéis, comportamentos, atividades, oportunidades e atributos baseados em diferentes níveis de poder no âmbito da sociedade; sendo distinto das categorias binárias do sexo biológico, embora interaja com estas. Seu entendimento requer, assim, a compreensão dos complexos processos sociais que operam no nível interpessoal, das instituições e da sociedade como um todo. Portanto, o gênero é um 
Questões de gênero na consulta pré-natal de enfermagem: percepções das... | 4

determinante da saúde, visto que se inter-relaciona com outros fatores de desigualdade, discriminação, marginalização e exclusão social, cujos efeitos na saúde e no bem-estar dos indivíduos são complexos. ${ }^{5}$

No âmbito da saúde, mulheres e homens estão fortemente sujeitos às normalizações sociais, comumente expressas por representações de maternidade e paternidade permeadas de valores tradicionais restritivos de papéis sociais igualitários. Desse modo, as normas de gênero contribuem para moldar um sistema desigual no qual os programas e ações governamentais relativos à maternidade dão ênfase à figura da mãe, que possibilita o nascimento do filho, e situam o pai como coadjuvante, relegando temas importantes como a gravidez indesejada, o aborto, a violência, dentre outras. ${ }^{6}$

Frente a essas questões, a assistência pré-natal intenta ser um momento de acolhimento e escuta sensível, bem como visa possibilitar o respeito à dignidade e autonomia da gestante, favorecer a participação ativa do parceiro e promover a igualdade de gênero nas vivências de maternidade e paternidade. Assim sendo, é esperado que o profissional de enfermagem demonstre sensibilidade e habilidades para abordar as questões de gênero nesse momento da vida reprodutiva. ${ }^{7}$

Apesar dessas premissas, o atual contexto sociocultural e político tem despertado perspectivas que vão na contramão da igualdade de gênero no campo da saúde. Em vista disso, exige-se o envolvimento de todos os atores sociais defensores dos direitos humanos para evitar possíveis retrocessos e perdas das conquistas no campo dos direitos sexuais e reprodutivos. ${ }^{8}$

Ante esses desafios para a promoção da igualdade de gênero em saúde, espera-se que as enfermeiras sejam qualificadas para a assistência pré-natal de forma a desenvolverem sensibilidade e competências de acordo com as metas previstas nos ODS e na Política Nacional de Atenção Integral à Saúde da Mulher (PNAISM). Diante de tais desafios e recomendações, a presente pesquisa foi proposta a partir da seguinte questão: como as enfermeiras em processo de qualificação para a assistência pré-natal percebem as questões de gênero na consulta de 
5 | Nascimento CM, Barbosa DSP, Pereira ALF, Mouta RJO, Silva SCSB

enfermagem? Destaca-se que essa consulta é uma prática privativa da enfermeira, estabelecida pelos programas de saúde da Atenção Básica e Saúde da Mulher no Brasil. Entre outras ações, essa profissional desenvolve a consulta pré-natal para as mulheres grávidas e saudáveis, assumindo importante papel na melhoria do acesso e qualificação da assistência, em conformidade com as recomendações dos programas de saúde - que incluem a equidade de gênero -, a fim de obter melhores resultados e prevenir desfechos maternos e neonatais negativos.

O estudo objetivou descrever as percepções das enfermeiras residentes em processo de qualificação para a assistência pré-natal acerca das questões de gênero na consulta de enfermagem.

\section{Método}

Estudo qualitativo, do tipo descritivo, realizado com enfermeiras residentes em processo de qualificação na assistência pré-natal, nos serviços públicos da APS do município do Rio de Janeiro. As enfermeiras participantes estavam matriculadas em programas de residência em enfermagem coordenados por uma Instituição de Ensino Superior (IES) pública.

A escolha por esse grupo se deveu ao fato de ser constituído, principalmente por profissionais que tinham finalizado recentemente o curso de graduação em enfermagem, que prevê a capacitação para a assistência pré-natal e a consulta de enfermagem. Nesse sentido, partiu-se do pressuposto de que o programa de residência promove experiências práticas em serviço que ampliam ou aprimoram as competências e habilidades previamente adquiridas no nível da graduação.

Foram incluídas na pesquisa as enfermeiras em processo de qualificação para a assistência pré-natal de gestantes de risco habitual, matriculadas em programas de residência, que realizavam ou participavam de consultas de enfermagem. Excluíram-se as enfermeiras residentes escaladas há menos de dois meses nesse tipo de assistência, a contar do início de suas atividades no programa. 
Questões de gênero na consulta pré-natal de enfermagem: percepções das... | 6

As enfermeiras participantes foram selecionadas de modo intencional, a partir de um grupo elegível de 28 enfermeiras matriculadas em programas de residência de enfermagem obstétrica e saúde da família, cujo treinamento em serviço contempla serviços da atenção prénatal, com consultas de enfermagem e no âmbito da APS. As enfermeiras elegíveis foram convidadas a participar da pesquisa no final das aulas teóricas semanais de seus respectivos programas de residência na IES. Ao demonstrarem interesse de participação e a partir da observância dos critérios de inclusão e exclusão descritos, foram contatadas para agendamento das entrevistas.

A captação de participantes elegíveis cessou quando houve recorrência dos temas que emergiram das falas das enfermeiras sobre as questões de gênero na consulta pré-natal de enfermagem, o que determinou o término das entrevistas. Ao total, foram entrevistadas 12 enfermeiras. A coleta de dados foi realizada de outubro a novembro de 2016.

Optou-se por realizar as entrevistas na própria sala de aula dos respectivos programas, antes ou depois das aulas teóricas, em virtude de ser um ambiente mais reservado para a concessão da entrevista. As entrevistas individuais foram conduzidas, sob a supervisão de uma pesquisadora da equipe, por acadêmicas de enfermagem previamente treinadas, bem como orientadas por um roteiro semiestruturado, testado anteriormente com duas enfermeiras voluntárias, cujas entrevistas-piloto foram excluídas.

O roteiro constituiu-se de três perguntas cujo objetivo era caracterizar as participantes quanto à idade, ao tempo de conclusão da graduação em enfermagem e ao tempo de atuação em consultas de pré-natal durante a residência. Essas perguntas foram acrescidas de questões abertas relativas às questões de gênero na consulta pré-natal de enfermagem, a saber: Fale-me sobre as questões de gênero que surgem no período da gestação, aquelas que são específicas ou relativas ao gênero feminino e ao gênero masculino neste período e como estas questões devem ser abordadas na consulta pré-natal de enfermagem. 
Os dados foram analisados pela análise de conteúdo temática. Procedeu-se à pré-análise por meio da organização das entrevistas e leitura exaustiva dos conteúdos textuais para identificar os recortes de texto atinentes ao objeto de estudo; exploração do material com utilização da equivalência semântica dos códigos, segundo os temas correspondentes, e construção das categorias temáticas; inferência e interpretação com base na literatura científica sobre as questões de gênero na assistência de saúde materna e período pré-natal. ${ }^{9}$

O estudo respeitou as normas regulamentadoras das pesquisas que envolvem os seres humanos, tendo sido aprovado pelo Comitê de Ética em Pesquisa da Universidade do Estado do Rio de Janeiro em 17 de abril de 2015, obtendo Parecer nº 1.028.107 e CAAE 40647415.9.0000.5282. Adotou-se a codificação para garantir o anonimato das participantes, por meio da letra E seguida da ordem de concessão das entrevistas: E1, E2, E3, e assim por diante. Todas as participantes assinaram o Termo de Consentimento Livre e Esclarecido.

\section{Resultados}

As 12 enfermeiras em qualificação na assistência pré-natal, participantes do estudo, eram predominantemente mulheres, com idade entre 24 a 33 anos. Apenas dois profissionais eram do sexo masculino. Optou-se por designar os participantes pelo gênero predominante entre eles, o feminino.

Essas profissionais tinham concluído a graduação em enfermagem há cerca de 24 meses, em média, com variação de dez meses a quatro anos, e atuavam na consulta pré-natal de enfermagem entre dois a nove meses, desde o início de sua qualificação, em unidades de saúde da APS. Esse grupo de participantes compôs-se de cinco enfermeiras matriculadas no Programa de Residência em Enfermagem Obstétrica e sete profissionais que cursavam a Residência em Enfermagem da Saúde da Família. 
A análise de conteúdo temática possibilitou a construção de duas categorias: Estereótipos de gênero percebidos pelas enfermeiras residentes na consulta pré-natal de enfermagem e Promoção da equidade de gênero na assistência pré-natal.

\section{Estereótipos de gênero percebidos pelas enfermeiras residentes na consulta pré-natal de enfermagem}

As enfermeiras consideram que a maternidade e a paternidade são estruturadas pelos papéis de gênero tradicionalmente atribuídos à mulher e ao homem. Os assuntos e cuidados com a gravidez, o parto e os filhos competem às mulheres, enquanto os homens têm a responsabilidade do sustento da família.

A sociedade impõe que é a mulher que tem que cuidar da criança. É a mulher que participa, mas o homem só fica ali do lado e não ajuda quase nada. (E11)

Essa questão da criação do filho, a mulher tem essa obrigação de criar e de educar, e o homem acha que não é atributo dele. (E5)

Quanto a essas limitações, as enfermeiras caracterizam as gestantes pela fragilidade e submissão em relação ao gênero masculino, como manifestam os seguintes depoimentos:

No homem, eu vejo mais essa questão da autoridade e um maior empoderamento. Ele tem mais poder do que a mulher dentro de um relacionamento, é a visão que eu tenho de todas as consultas de pré-natal quando aparecem, eu já sei disso. Então, quando você tem essa questão do gênero, quando você tem essa questão da força de quem manda dentro da familia, ele quem manda e trabalha. Ela não, está grávida e em casa. Então, acaba se deixando levar. (E6)

A mulher pode ficar muito frágil devido às mudanças [gestacionais] ocorridas em seu corpo. Ela fica infinitamente mais frágil, porque ela não está dentro dos padrões estabelecidos pela sociedade como um todo e 
9 | Nascimento CM, Barbosa DSP, Pereira ALF, Mouta RJO, Silva SCSB

talvez estabelecidos até intrafamiliar. Muitas vezes, eu atendo mulheres que ficam preocupadas com o corpo: E agora? Eu estou gorda e o meu marido vai procurar uma mulher mais magra! Aí, você para e pensa: Não é possível ouvir isso em pleno século XXI! Mas se ouve muito. É difícil. (E11)

$\mathrm{Na}$ percepção das enfermeiras, as iniquidades de gênero estão associadas com as situações de violência e o limitado apoio social que as mulheres vivenciam no período da gravidez.

A mulher fica cheia de dúvidas, quer buscar apoio nas pessoas e nem sempre elas dão apoio. A questão de violência acontece muito na gestação, mais do que se imagina. (E1)

Gravidez pode vir de um sexo que elas não queriam fazer, mas fizeram para agradar. Uma mulher que não queria ficar grávida, mas engravidou por causa do marido que a pressiona ou porque, se elas não cederem, o marido procura outra. (E8)

Quando se pensa em uma mulher que esteja sofrendo abusos em relação à questão do trabalho, às vezes tem uma chefia masculina e ela fica muito submissa com as questões trabalhistas e tem medo de ser agredida de alguma forma. A violência psicológica é muito comum, principalmente com as gestantes. (E10)

No que concerne aos parceiros, as participantes reconhecem que há um movimento de mudança no papel paterno tradicional, pois há homens que buscam envolver-se com a gravidez da parceira e exercer uma paternidade mais ativa.

A sociedade impõe que a mulher tem que cuidar da criança, é a mulher que participa mais. E no final, o homem só fica ali do lado e não ajuda quase nada. Mas já está mudando com a questão do acompanhante e do pai presente no alojamento conjunto. A gente tenta trazer o parceiro o tempo inteiro para ajudar a mulher a cuidar e que ele tem esse dever também. A princípio, existia preconceito, mas eles já estão mais abertos. Alguns têm certa resistência, geralmente os homens da geração mais velha, mas tem outros que já chegam mais abertos. (E12) 
Questões de gênero na consulta pré-natal de enfermagem: percepções das... $\mid 10$

Sobre as minorias de gênero, as enfermeiras relatam que casais homoafetivos procuram o atendimento pré-natal nos serviços onde atuam. Esses casais suscitam desafios à organização da assistência pré-natal, delineada, tradicionalmente, para casais heterossexuais, o que mobiliza atitudes de preconceito e expõe as limitações existentes na abordagem das questões de gênero no cotidiano assistencial.

Eu acho que tem o gênero e a identidade de gênero. Para mim, o gênero é quando a pessoa é masculino ou feminino. A identidade é como ela se identifica, ela pode ser um homem, mas se identificar como uma mulher e vice-versa. Eu já tive no pré-natal uma menina que era lésbica e tinha uma namorada, mas elas brigaram. Ela foi para uma boate e bebeu, teve relações sexuais com um cara, ficou grávida e manteve a gravidez. Mas não tem abordagem de gênero no pré-natal, o que eu participei não teve essa abordagem. As pessoas não abordam essa questão do gênero no pré-natal. Infelizmente, elas não sabem como aplicá-la. (E4)

A mulher tem essa questão de carregar tudo nas costas, inclusive se ela tem uma companheira. Se ela já sofre como casal heteronormativo, um casal homonormativo é mais complicado para a sociedade. Deveria ser normal para a gente tratar desse tipo de casal, mas o país é ultrapreconceituoso, machista e LGBTfóbico. (E2)

Assim, os depoimentos das enfermeiras residentes corroboram as assertivas sobre as limitações da abordagem de gênero na formação em enfermagem, pois reconhecem que há atitudes de preconceito contra os casais homoafetivos no atendimento pré-natal e que elas próprias vivenciam conflitos morais devido a seus valores pessoais alicerçados na heteronormatividade.

Eu não sei como é agora, mas a abordagem de gênero foi praticamente zero na minha graduação, muito pouco, mais para o final mesmo. E também teve um aluno que fez a monografia sobre gênero, mas é muito pouco abordado. Eu acho que tenho dificuldade nesse assunto, 
principalmente na prática. Não é que eu tenha preconceito, não sei se você me entende. Eu não tive essa criação porque eu venho de uma família muito tradicional e isso não é natural[homossexualidade]. Eu não vejo isso com tanta naturalidade, embora não julgue, mas tem coisas que ainda causam um impacto para mim. (E8)

\section{Promoção da equidade de gênero na assistência pré-natal}

As participantes consideram que o estímulo ao empoderamento feminino nas consultas pré-natal de enfermagem é imperativo para o enfrentamento das desigualdades de gênero ainda arraigadas na sociedade.

Empoderar a mulher, o papel que ela deve ter e não simplesmente se sentir menosprezada ou menor. É realmente empoderar a mulher do poder dela, a posição de igualdade no mundo e no mercado [de trabalho], a importância de ser proativa e ter o seu espaço reconhecido na sociedade. E discutir essa questão com o casal e a família como um todo. (E9)

As enfermeiras destacam a importância da atitude ética do profissional de enfermagem durante a consulta pré-natal, que inclui o sigilo profissional; a postura de acolhimento da mulher, parceiro(a) e família; e a criação de vínculo e diálogo aberto, como expressam os seguintes depoimentos:

Então, primeiro é o sigilo profissional. Demonstrar o seu sigilo profissional, você consegue manter o cuidado dela. E tem que deixar claro para ela que tudo que for conversado ali dentro não vai ser passado para ninguém. Ninguém vai expor a vida dela. (E7)

Você tem que ter empatia. Se você tem empatia e mostrar o seu sigilo profissional, você consegue conquistar essa mulher. Se você não tiver, não consegue um cuidado decente para aquela pessoa. Então, sem você conhecer a vida dela fica mais difícil você perguntar, como fazer ao abordar isso [questões de gênero] e ter respeito. Se não tiver respeito na sua abordagem, você também não consegue e muitas pessoas fogem e vão 
Questões de gênero na consulta pré-natal de enfermagem: percepções das... | 12

procurar outro serviço ou, então, ficam naquelas meias palavras e não te respondem. (E1)

O incentivo à participação paterna durante o pré-natal também foi percebido como necessário à promoção da equidade de gênero, como evidenciam os depoimentos das enfermeiras.

O serviço de pré-natal também não cria estratégias para esse homem ir para a consulta. Se você não criar estratégia, ela vai seguir o pré-natal inteiro sem você conhecer o pai da criança, você não conhece o parceiro, marido, namorado. Então, também é fundamental incluir o homem nesse conceito de pré-natal e também para a mulher, mostrar para ela que a gravidez é dos dois e não só dela, as responsabilidades são dos dois. (E4)

Eu tento estimular que o homem participe das consultas de pré-natal. Alguns até consegui, mas outros não, até pela questão da produção independente. Às vezes, também tem a questão do horário de atendimento e temos que priorizar o horário que o pai ou o parceiro pode estar presente. (E3)

\section{Discussão}

Apesar dos avanços no papel social das mulheres, os homens ainda são vistos como os principais provedores e tomadores de decisão na família; e essas concepções podem influenciar negativamente no acesso das mulheres aos serviços da atenção materno-infantil, sobretudo nos países em desenvolvimento. ${ }^{10-11}$ Nesse sentido, as normas sociais, aliadas a fatores religiosos, contribuem para o baixo envolvimento masculino durante a gestação, parto e cuidados do bebê, bem como para a manutenção de posturas femininas de oposição ou restrição à presença dos homens nesses momentos, o que repercute na efetividade e impacto dos resultados de saúde. ${ }^{5,11}$

Os depoimentos das enfermeiras residentes expressaram ideias estereotipadas, uma vez que apontaram a fragilidade e a maternidade como elementos-chave da identidade feminina, ao passo que se referiram à fortaleza e posição de liderança dos homens na família e na sociedade. No entanto, discordaram de tais concepções cristalizadas, que refletem a visão essencialista 
construída por uma ordem social que naturaliza o domínio masculino; por meio da qual normas, valores e comportamentos sociais são pautados nas desigualdades de gênero e poder, inclusive determinam padrões de feminilidade e masculinidade que se manifestam nas estruturas e processos de opressão e discriminação sociais..$^{4-5}$

Quanto às desigualdades, há cruzamento entre o gênero e outros fatores de discriminação, marginalização e exclusão social, como etnia, classe, status socioeconômico, deficiência, idade, localização geográfica, orientação sexual e identidade sexual. Esse conjunto de fatores causa efeitos complexos na saúde e no bem-estar dos indivíduos e da comunidade. ${ }^{4-5}$

Foram identificadas também barreiras socioculturais relacionadas ao gênero, que dificultam o acesso oportuno das mulheres aos cuidados de saúde. A esse respeito, a atitude do parceiro pode fazer com que a mulher postergue a tomada de decisão e a busca pelos serviços de saúde, em virtude de dependência financeira, reduzida autonomia para tomada de decisões e obrigações com a família. ${ }^{4,12}$

Assim, apesar dos avanços percebidos pelas enfermeiras residentes acerca da postura participativa de alguns homens, e embora as políticas de saúde estimulem o envolvimento paterno no pré-natal, verifica-se que, nos países em desenvolvimento, ainda há baixa participação masculina na gravidez e parto devido às normas sociais e do sistema de saúde. ${ }^{9-10}$ Ademais, as unidades de saúde tendem a ter ambientes estruturados e destinados ao público feminino, a exemplo das maternidades, o que pode fazer com que os homens se sintam desconfortáveis nesses locais. Nota-se, diante desses fatores, que as normas de gênero influem na participação masculina e na manutenção dos padrões tradicionais de feminilidade e masculinidade no âmbito da saúde e da sociedade. ${ }^{13-14}$

Contudo, a discriminação de gênero representa um obstáculo para a qualidade da assistência à saúde materna. Essa problemática requer a criação de estratégias eficazes para lidar com os maus-tratos nos serviços, sobretudo no parto; estrutura baseada em direitos a fim 
Questões de gênero na consulta pré-natal de enfermagem: percepções das... | 14

de promovê-los e dar voz às mulheres; diretrizes clínicas e protocolos nacionais com perspectivas sensíveis ao gênero e baseados em direitos; e sistema de monitoramento que abarque os indicadores de gênero. ${ }^{12-13}$ Nesse sentido, há evidências de que o envolvimento do parceiro pode impactar positivamente na utilização dos serviços de saúde materna e infantil, por exemplo, pode melhorar a utilização dos serviços de saúde pelas companheiras e diminuir a probabilidade de complicações no parto e de depressão materna. ${ }^{11-12}$

Estudo de revisão, realizado em países desenvolvidos e em desenvolvimento, constatou que o envolvimento masculino traz benefícios à saúde materna: maior acesso materno aos serviços de pré e pós-natal; redução de práticas maternas prejudiciais como o fumo; melhoria na saúde mental materna; maior probabilidade de uso de contraceptivos; e alívio do estresse, dor e ansiedade durante o parto. Em contraponto, ressaltaram desvantagens como o aumento do domínio masculino na tomada de decisões e o potencial de causar maior dificuldade no trabalho de parto devido à ansiedade paterna no centro obstétrico. Assim, a meta-análise concluiu que o envolvimento masculino está associado a melhores resultados de saúde materna nos países em desenvolvimento, mas apontou escassez de estudos robustos sobre o tema nesses países. ${ }^{12}$

Quanto aos programas de saúde direcionados para o estímulo da participação masculina, verificou-se que os programas sem enfoque nas normas de gênero foram insuficientes para efetivar mudanças significativas nas relações sociais em saúde materna, pois os resultados foram modestos e limitados no que concerne à melhoria dos indicadores de saúde. ${ }^{13-14}$ Nessa perspectiva, há uma complexa relação entre gênero e equidade em saúde que abarca três domínios interligados: os determinantes sociais, os comportamentos em saúde e as respostas do sistema de saúde. Além disso, as iniquidades de gênero se manifestam nos sistemas de saúde e afetam todas as áreas da vida social, como educação, saúde e trabalho, sobretudo para as mulheres, ocasionando disparidades salariais, violência física e sexual, representação restrita na liderança e tomada de decisões, entre outras desigualdades. ${ }^{5}$ 
15 | Nascimento CM, Barbosa DSP, Pereira ALF, Mouta RJO, Silva SCSB

Em face dessas limitações, os ODS, como já mencionado, buscam impulsionar a igualdade de gênero e combater as desigualdades historicamente construídas entre mulheres e homens. No entanto, as normas restritivas de gênero ainda comprometem a saúde e o bem-estar das comunidades e indivíduos, não apenas das mulheres, mas também dos homens e minorias de gênero. ${ }^{14-15}$

No contexto mais amplo das questões de gênero, as enfermeiras residentes externaram o despreparo dos serviços em prestar cuidados adequados a essa clientela, apesar da tendência atual de os casais do mesmo sexo acessarem cada vez mais os serviços de saúde reprodutiva. Estudos sobre o tema demonstram que essas pessoas tendem a receber cuidados menos igualitários em comparação aos heterossexuais. ${ }^{16-17}$

As mulheres que se declaram lésbicas, gays, bissexuais, travestis, transexuais, ou que se identificam com outras formas de gênero e sexualidade (LGBTT+), enfrentam rejeição, desrespeito, isolamento e julgamento que afetam negativamente o seu relacionamento e comunicação com os profissionais de saúde. Esse grupo social tem receio de externar a sua orientação sexual aos profissionais e passa por experiências de insensibilidade, ignorância e tratamento tendencioso decorrente do heterossexismo organizacional dos serviços de saúde, que causa discriminação, intolerância e julgamento moral no atendimento de saúde. ${ }^{17-18}$

Estudo israelense revelou que a maioria das enfermeiras que cuidam das mulheres lésbicas, desde o planejamento da gravidez até o nascimento, não recebeu treinamento específico para compreender as necessidades específicas da população LGBTT+, que abarcam o processo de construção da identidade sexual e o papel exercido por cada um dos parceiros de mesmo sexo no relacionamento conjugal, a geração e a criação dos filhos. Apesar das mudanças observadas nas atitudes profissionais em relação à homossexualidade, verificou-se que a discriminação ainda é bastante comum. ${ }^{18}$ 
Questões de gênero na consulta pré-natal de enfermagem: percepções das... | 16

Outro aspecto relevante é que os homens transgêneros são designados como mulheres no nascimento, mas se identificam como homens. Embora alguns realizem tratamento hormonal e/ou cirurgia que desfavorecem uma gravidez, muitos preservam os órgãos reprodutivos femininos e, por consequência, a sua capacidade de engravidar. Porém, apesar do aumento da visibilidade social das pessoas transgêneros, ainda são limitadas as pesquisas sobre o tema, bem como as experiências dos profissionais de saúde com homens transgêneros que engravidam. ${ }^{17-19}$

Estudo com homens transexuais maiores de 35 anos constatou que os desejos reprodutivos desses indivíduos são semelhantes aos dos cisgêneros, aqueles cuja identidade de gênero corresponde ao gênero atribuído no nascimento. Alguns homens transgêneros também podem ter gestações altamente desejadas e outros consideram que a gravidez é necessária para iniciar uma família. ${ }^{17}$

Portanto, em um mundo heteronormativo, os profissionais de saúde podem se sentir despreparados e pouco confortáveis no atendimento das pessoas LGBTT+, o que predispõe a inequidades nos cuidados à saúde dessa população. ${ }^{16-18}$ Esse despreparo sinaliza que a temática gênero precisa ser adequadamente contemplada no ensino de enfermagem, pois o cuidado deve ser norteado pelos princípios éticos que balizam a profissão e pelos direitos inalienáveis da pessoa humana, que incluem os direitos sexuais e reprodutivos.

Por outro lado, os homens transexuais têm gestações indesejadas. Pesquisa com esses homens que vivenciaram gravidez e parto identificou que cerca de $30 \%$ deles não desejavam engravidar. A maioria teve o seu pré-natal acompanhado por médicos, mas também por enfermeiras obstétricas $(28 \%)$, e pariu por via vaginal (64\%) no hospital, enquanto uma menor parcela teve o parto no domicílio $(17 \%)$ e em centro de parto normal $(5 \%){ }^{19}$ Frente a essa realidade emergente, alerta-se para a importância de debates sobre as experiências da população LGBTT+ em saúde reprodutiva e os direitos que essas pessoas têm de receber cuidados de saúde qualificados e adequados às suas questões de gênero..$^{16,19}$ 
Para a adequação da assistência pré-natal e obtenção de melhores resultados de saúde, as enfermeiras residentes consideram que a promoção da equidade de gênero deve estimular o empoderamento feminino, pois possibilita maior capacidade pessoal de fazer escolhas estratégicas na vida em face de um contexto histórico no qual essa capacidade ainda é negada. Esse estímulo propicia que as mulheres aumentem a autoconfiança e afirmem o direito de fazer escolhas e lhes dá acesso a recursos que podem auxiliá-las na superação da dependência econômica e subordinação..$^{5,14}$

Diante do exposto, torna-se claro que o sistema de saúde precisa considerar o impacto do gênero no status social e de saúde do indivíduo e da comunidade. Além disso, necessita adotar boas práticas em direitos humanos para evitar os danos consequentes da reprodução das dinâmicas de gênero e poder, como os relatados na assistência a mulheres e grupos minoritários. ${ }^{5}$

Espera-se, desse modo, que as enfermeiras sejam capazes de proporcionar acolhimento, estabelecer uma relação de confiança e prestar cuidados respeitosos e qualificados às pessoas, famílias e comunidades. ${ }^{1}$ Quanto ao pré-natal, além de visarem a manutenção do bem-estar físico e emocional da gestante e do concepto, recomenda-se que realizem a promoção da saúde por meio de informações e orientações sobre a gravidez, parto e pós-parto. Devem também buscar o estímulo ao empoderamento feminino, para favorecer a autoconfiança da mulher no exercício do seu direito à livre escolha, à tomada de decisões e à autonomia, possibilitando-lhe vivenciar esses momentos com protagonismo e a maternidade de forma plena, prazerosa, com participação ativa do parceiro e apoio da família..$^{1-2,7}$

No que tange à promoção da equidade na assistência pré-natal, apesar das complexidades relacionadas às questões de gênero, as propostas das enfermeiras participantes listam as atitudes profissionais necessárias ao cuidado das mulheres e parceiros(as), como a postura profissional ética e de acolhimento, estímulo ao empoderamento feminino e ao aumento da participação masculina no cuidado materno. São, contudo, propostas direcionadas para o nível 
Questões de gênero na consulta pré-natal de enfermagem: percepções das... | 18

individual do atendimento da gestante e companheiro(a), que não abarcam estratégias coletivas integradas ao processo assistencial do serviço e suas possíveis interfaces com o sistema de saúde e demais setores da vida social, embora reconheçam que há limitações na abordagem das questões de gênero no cotidiano assistencial dos serviços.

Porém, a diminuição da desigualdade de gênero envolve desafios estruturais ou sistêmicos que vão além da compreensão e aferição dos efeitos das normas de gênero sobre o indivíduo e sua saúde. Assim, as estratégias que intentam diminuir essa desigualdade devem ser diversificadas e intersetoriais, contemplando a participação social, bem como ações que incentivem o empoderamento juntamente com a promoção da saúde. Somente uma abordagem sistêmica, em âmbito micro e macrossocial, possibilita que os valores e atitudes dos indivíduos e as experiências de saúde ancoradas em desigualdades sociais e de gênero sejam modificadas. ${ }^{20}$

Nessa perspectiva, o grupo de enfermeiras do estudo aqui descrito demonstra reconhecer as questões de gênero que emergem na consulta pré-natal e suas influências sobre a saúde materna. Contudo, elas afirmam não conhecerem experiências cotidianas promotoras da saúde com perspectiva de gênero nos serviços onde ocorre a qualificação profissional, o que pode denotar uma possível persistência do enfoque clínico na assistência.

Ressalta-se que o enfoque clínico é considerado restrito em saúde e pode ser visto como consoante, de forma consciente ou inconsciente, com o atual contexto político e sanitário que limita os projetos ampliados e democráticos em prol da saúde pública, participação social, equidade de gênero e do empoderamento das mulheres. ${ }^{8}$ Essas limitações são desafios para o ensino e assistência de saúde e enfermagem, demandando que a academia e o serviço elaborem estratégias de enfrentamento das iniquidades de gênero aplicadas à prática assistencial a fim de melhorar a efetividade dos seus resultados.

Por fim, os limites do presente estudo devem ser destacados, uma vez que analisou as percepções de um grupo limitado de enfermeiras que estavam se qualificando na assistência 
19 | Nascimento CM, Barbosa DSP, Pereira ALF, Mouta RJO, Silva SCSB

pré-natal em programas de residência; por esse motivo, os seus resultados devem ser contemplados com cautela por não serem representativos da diversidade de realidades e perspectivas das enfermeiras no âmbito da assistência pré-natal.

\section{Conclusão}

As enfermeiras em qualificação para a assistência pré-natal consideram que as normas, valores e comportamentos femininos e masculinos frente à maternidade e à paternidade são determinados pelos papéis tradicionais de gênero, e que as iniquidades de gênero dão origem a situações de violência contra as mulheres e à baixa participação masculina no período gestacional de suas parceiras, sugerindo que as participantes do estudo reconhecem a influência das questões de gênero na assistência.

As enfermeiras também trazem à luz questões emergentes na sociedade, como o aumento de homens com postura participativa nos cuidados da parceira grávida e a busca de casais homoafetivos pelo atendimento pré-natal, sendo que esses casais ainda suscitam preconceitos e situações inquietantes para os profissionais de saúde.

As participantes sugerem que a abordagem das questões de gênero deve contemplar o empoderamento feminino e a participação masculina no cuidado materno; além disso, mencionam a importância de o profissional prestar cuidados com postura ética e de acolhimento, mas reconhecem limitações nessa abordagem nos serviços onde estão se qualificando. A promoção da equidade de gênero na assistência pré-natal foi concebida apenas no nível individual do atendimento e não como integrante das ações de promoção da saúde no serviço.

Essa percepção restrita impõe à academia e ao serviço a necessidade de trabalharem em conjunto para a concepção, implementação e avaliação de propostas de intervenção que incorporem a perspectiva de gênero na assistência pré-natal, favoreçam a aderência dos profissionais e 
Questões de gênero na consulta pré-natal de enfermagem: percepções das... $\mid 20$

sensibilizem a clientela para que a relação entre gênero e saúde seja discutida, permitindo melhorias nos resultados da saúde e avanços na qualificação profissional em saúde e enfermagem.

Espera-se que os achados aqui descritos possam contribuir para o debate acerca dos desafios persistentes e emergentes relacionados ao gênero, assim como dos avanços necessários ao ensino, à assistência e à pesquisa sobre o tema da equidade de gênero em saúde e enfermagem, abordagem de gênero no cuidado pré-natal e perspectiva de gênero ampliada e não binária em saúde reprodutiva nos serviços da APS.

\section{Referências}

1. Ministério da Saúde (BR), Secretaria de Atenção à Saúde, Departamento de Atenção Básica. Atenção ao pré-natal de baixo risco. Brasília (DF): Ministério da Saúde; 2012.

2. Silva AA, Jardim MJA, Rios CTF, Fonseca LMB, Coimbra LC. Pré-natal da gestante de risco habitual: potencialidades e fragilidades. Rev Enferm UFSM [Internet]. 2019 [cited 2019 Dec 10];9:e15. Available from: https://periodicos.ufsm.br/reufsm/article/view/32336

3. Mario DN, Rigo L, Boclin KLS, Malvestio LMM, Anziliero D, Horta BL, et al. Quality of prenatal care in Brazil: national health research 2013. Ciênc Saúde Colet. 2019;24(3):1223-32. doi: 10.1590/141381232018243.13122017

4. Hay K, McDougal L, Percival V, Henry S, Klugman J, Wurie H, et al. Disrupting gender norms in health systems: making the case for change. Lancet. 2019;393(10190):2535-49. doi: 10.1016/S01406736(19)30648-8

5. Manandhar M, Hawkes S, Buse K, Nosrati E, Magar V. Gender, health and the 2030 agenda for sustainable development. Bull World Health Organ. 2018;96(9):644-53. doi: 10.2471/BLT.18.211607

6. Oliveira ECS, Pezzato LM, Mendes R. Às margens do cuidado: regulações de gênero em uma equipe de saúde. Physis. 2018;28(2):e280208. doi: 10.1590/s0103-73312018280208

7. Jardim MJA, Silva AA, Fonseca LMB. The nurse's contributions in prenatal care towards achieving the pregnant women empowerment. Rev Pesq Cuid Fundam. 2019;11(Spec No):432-40. doi: 10.9789/21755361.2019.v11i2.432-440

8. Zanatta LF, Grein MI, Álvarez-Dardet C, Moraes SP, Brêtas JRS, Ruiz-Cantero MT, et al. Gender equality: why is Brazil moving backwards? Cad Saúde Pública. 2016;32(8):e00089616. doi: 10.1590/0102311X00089616 
9. Bardin L. Análise de conteúdo. São Paulo: Edições 70; 2011.

10. Manda-Taylor L, Mwale D, Phiri T, Walsh A, Matthews A, Brugha R, et al. Changing times? Gender roles and relationships in maternal, newborn and child health in Malawi. BMC Pregnancy Childbirth. 2017;17(1):321. doi: 10.1186/s12884-017-1523-1

11. Sharma V, Leight J, Giroux N, AbdulAziz F, Nyqvist MB. "That's a woman's problem": a qualitative analysis to understand male involvement in maternal and newborn health in Jigawa state, northern Nigeria. Reprod Health. 2019;16(1):143. doi: 10.1186/s12978-019-0808-4

12. Yargawa J, Leonardi-Bee J. Male involvement and maternal health outcomes: systematic review and meta-analysis. J Epidemiol Community Health. 2015;69(6):604-12. doi: 10.1136/jech-2014-204784

13. Betron ML, McClair TL, Currie S, Banerjee J. Expanding the agenda for addressing mistreatment in maternity care: a mapping review and gender analysis. Reprod Health. 2018;15(1):143. doi: 10.1186/s12978018-0584-6

14. Mandal M, Muralidharan A, Pappa S. A review of measures of women's empowerment and related gender constructs in family planning and maternal health program evaluations in low- and middleincome countries. BMC Pregnancy Childbirth [Internet]. 2017 Nov [cited 2019 Dec 15];17(Suppl 2):342. Available from: https://dx.doi.org/10.1186/s12884-017-1500-8

15. Gupta GR, Oomman N, Grown C, Conn K, Hawkes S, Shawar YR, et al. Gender equality and gender norms: framing the opportunities for health. Lancet.2019;393(10190):2550-62. doi: 10.1016/S01406736(19)30651-8

16. Araujo LM, Penna LHG, Carinhanha JI, Costa CMA. The care to lesbian women in the field of sexual and reproductive health. Rev Enferm UERJ. 2019;27:e3426. doi: 10.12957/reuerj.2019.34262

17. Brandt JS, Patel AJ, Marshall I, Bachmann GA. Transgender men, pregnancy, and the "new" advanced paternal age: a review of the literature. Maturitas. 2019;128:17-21. doi: 10.1016/j.maturitas.2019.07.004

18. Tzur-Peled S, Sarid O, Kushnir T. Nurses' perceptions of their relationships and communication with lesbian women seeking perinatal care. J Clin Nurs. 2019;28(17-18):3271-78. doi: 10.1111/jocn.14904

19. Light AD, Obedin-Maliver J, Sevelius JM, Kerns JL. Transgender men who experienced pregnancy after female-to-male gender transitioning. Obstet Gynecol. 2014;124(6):1120-27. doi: 10.1097/AOG.0000000000000540

20. Horgan SA, Chen SP, Tuininga T, Stuart H. Taking a closer look at gender-transformative health promotion programming as a vehicle for addressing gender-based inequities in health and care. Glob Health Promot. 2019 Aug;1757975919864109. doi: 10.1177/1757975919864109 
Questões de gênero na consulta pré-natal de enfermagem: percepções das... | 22

Editora Científica Chefe: Cristiane Cardoso de Paula

Editora: Tania Solange Bosi de Souza Magnago

\section{Autor correspondente}

Caroline Macedo do Nascimento

E-mail: carolzinhaah94@gmail.com

Endereço: Boulevard 28 de setembro n. 157/702. Vila Isabel, Rio de Janeiro-RJ.

CEP: CEP 20551-030

\section{Contribuições de autoria}

\section{1 - Caroline Macedo do Nascimento}

Concepção do estudo, análise e interpretação dos dados, redação do manuscrito.

\section{2 - Dayane da Silva Palha Barbosa}

Concepção do estudo, análise e interpretação dos dados, redação do manuscrito.

\section{3 - Adriana Lenho de Figueiredo Pereira}

Análise e interpretação dos dados; revisão final com participação crítica e intelectual no manuscrito.

\section{4 - Ricardo José Oliveira Mouta}

Revisão final com participação crítica e intelectual no manuscrito.

5 - Sandra Cristina de Souza Borges Silva

Redação e revisão final com participação crítica e intelectual no manuscrito.

\section{Como citar este artigo}

Nascimento CM, Barbosa DSP, Pereira ALF, Mouta RJO, Silva SCSB. Questões de gênero na consulta pré-natal de enfermagem: percepções das enfermeiras residentes. Rev. Enferm. UFSM. 2020 [Acesso em: Ano Mês Dia]; vol.10 e91: 1-22. DOI:https://doi.org/10.5902/2179769241974 